\title{
PERANCANGAN POWER BANK DENGAN MENGGUNAKAN DINAMO SEPEDA SEDERHANA
}

\author{
Alfi Ridwanto ${ }^{1, \mathrm{a}),}$ Wisnu Broto ${ }^{2, \mathrm{~b})}$ \\ Prodi Elektro Fakultas Teknik Universitas Pancasila, Srengseng Sawah, Jagakarsa, Jakarta Selatan 12640 \\ Email: a)alfiridwanto02@gmail.com, b)wisnu.agni@gmail.com
}

\begin{abstract}
Abstrak
Salah satu permasalahan yang sering timbul ketika dalam perjalanan menggunakan sepeda adalah daya baterai smartphone yang habis sebelum sampai tempat tujuan.Oleh karena itu dinamo sepeda adalah perangkat yang mengubah energi gerak menjadi listrik yang bersumber dari perputaran ban yang terjadi selama dijalan. Dikarenakan sumber dari dinamo adalah perputaran ban, maka hasil keluaran dari dinamo ini tidak stabil dikarenakan kecepatan yang berubah-ubah.Maka diperlukan suatu penyimpan energi untuk menampung energi listrik tersebut. Power bank adalah suatu peralatan yang digunakan untuk menyimpan energi dari dinamo dan digunakan untuk memindahkan muatan ke Smartphone dan handphone.
\end{abstract}

Kata-kata kunci: Smartphone, Power bank, Listrik

\begin{abstract}
One of the problems that often arise when in the course of using a bicycle is the battery smartphone that runs out before the destination. Therefore, the dynamo of a bicycle is a device that converts the energy of motion into electricity that comes from the rotation of tires that occur during the streets. Since the source of the dynamo is the tire rotation, the output of the dynamo is unstable due to the changing speed. So we need an energy storage to hold the electrical energy. The power bank is a device used to store energy from the dynamo and is used to transfer payloads to Smartphones and mobile phones.
\end{abstract}

Keywords: Smartphone, Power bank, Electric 


\section{PENDAHULUAN}

Dinamo sepeda merupakan mesin listrik yang mengubah energi mekanik menjadi energi listrik dengan menggunakan prinsip induksi elektromagnetis. Mesin ini merupakan generator sinkron yang berkapasitas kecil tergantung dari spesifikasinya seperti $6 \mathrm{~V} 6 \mathrm{~W}, 12 \mathrm{~V} 6 \mathrm{~W}, 12 \mathrm{~V} 12 \mathrm{~W}$, dan lain-lain . Pada sepeda, alat ini memanfaatkan putaran roda sepeda untuk menghasilkan listrik yang akan menyuplai beban berupa lampu. Tegangan yang dihasilkan dinamo bergantung kepada besarnya putaran sepeda yang memutar rotor dinamo. Semakin besar putaran maka semakin besar pula tegangan yang dihasilkan. Pada saat berputar dengan kecepatan ratingnya, tegangan yang dihasilkan dinamo adalah 13-14 volt. Dengan nilai tegangan itu, maka beban berupa lampu $12 \mathrm{~V}$ dapat menyala. Apabila perputaran ban sepeda sangat kencang dan tegangan yang dihasilkan sangat besar, maka beban yang berupa lampu dapat putus atau rusak jika tidak ada penambahan jumlah beban lainnya. Oleh karena itu dinamo sepeda biasanya dirancang berdasarkan kecepatan putar ban agar dapat menghasilkan tegangan yang sesuai dengan bebannya.

Salah satu permasalahan dalam energi listrik adalah keterbatasan sumber energi fosil yang merupakan sumber utama penghasil energi listrik di Indonesia, maka dibutuhkan energi terbarukan. Dinamo sepeda adalah perangkat yang mengubah energi gerak menjadi listrik yang bersumber dari perputaran ban depan sepeda .Dikarenakan sumber dari putaran roda ban sepeda , maka hasil keluaran dari dinamo ini tidak stabil dikarenakan perubahan kecepatan.Maka diperlukan suatu penyimpan energi untuk menampung energi listrik tersebut. Power bank adalah suatu peralatan yang digunakan untuk menyimpan energi dari dinamo dan digunakan untuk men-charge Smartphone.

\section{METODE PENELITIAN}

Secara umum diagram alir perancangan powerbank menggunakan dinamo sepeda dapat dilihat pada gambar di bawah ini

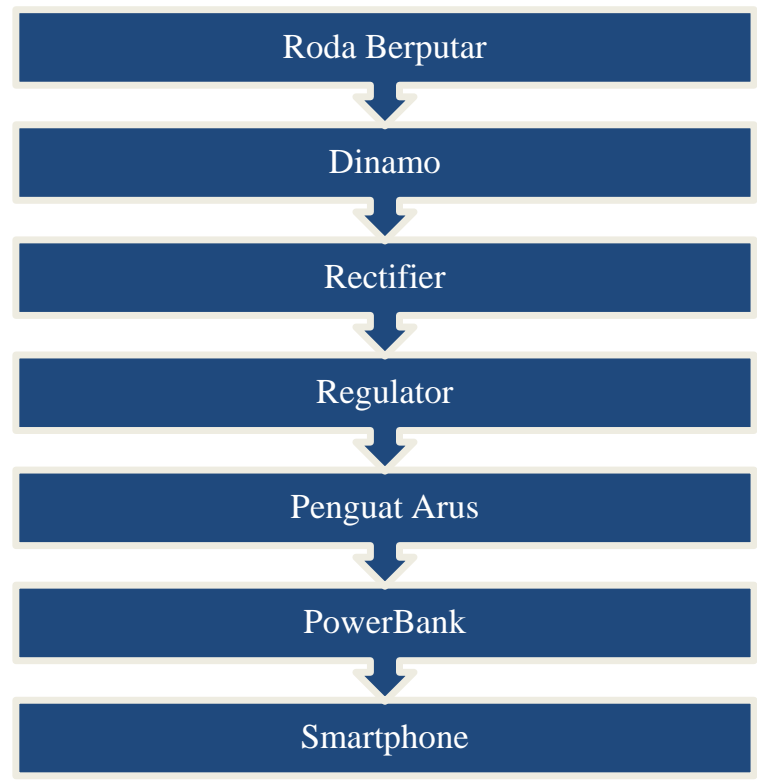

Berikut penjelasan mengenai komponen-komponen yang digunakan dalam perancangan ini:

\subsection{Dinamo}

Dinamo dibedakan menjadi dua yaitu, dinamo arus searah (DC) dan dinamo arus bolakbalik (AC). Prinsip kerja dinamo sama dengan generator yaitu memutar kumparan di dalam medan magnet atau 
memutar magnet di dalam kumparan. Bagian dinamo yang berputar disebut rotor. Bagian dinamo yang tidak bergerak disebut stator.

Dinamo sepeda intinya adalah sebuah magnet yang dapat berputar dan sebuah kumparan tetap apabila roda sepeda diputar dan dinamo akan berputar sehingga roda akan memutar magnet, biasanya dinamo dapat menghasilkan tegangan 6 sampai 12 Volt dan menghasilkan arus sekitar 450 mA.

Dinamo terdiri atas banyak kumparan gulungan kawat dinamo yang dapat berotasi pada sebuah medan magnet. Poros dinamo dapat dibangkitkan oleh beberapa cara mekanis. GGL pada dinamo menyebabakan rotasi di dalam gulungan sehingga arus listrik keluar dari sebuah generator. Selama setengah putaran ab memotong garis dari atas ke bawah dalam arah yang berlawanan. Demikian terjadi gaya gerak listrik dan arus listrik sewaktu melalui garis netral dan berbalik arah. Arus listrikakan mengalir selama lingkaran kawat diputar.

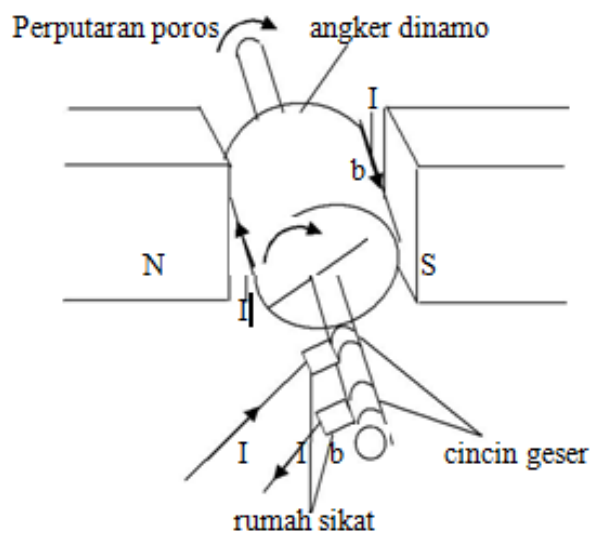

Gambar 1. Dinamo

Pada Gambar 1 loop bergerak searah dengan jarum jam pada medan magnet seragam dengan kecepatan putar konstantan $\omega$ Dari hukum Faraday "perubahan sudut antara magnetic B dan arah bidang normal dapat menimbulkan ggl induksi” dengan persamaan:

$$
\varepsilon=-\frac{d \Phi_{B}}{d t}=-\frac{d}{d t} \int B \cdot d A=-\frac{d}{d t}[B A \cos \theta]
$$

Dengan:

A = luas daerah loop

$\Theta=$ sudut antara $\mathrm{B}$ dan $\mathrm{A}$

$$
\omega=\frac{d \theta}{d t}
$$

Dimana $\Theta=\Theta 0+\omega t$

Sehingga $\Theta 0$ menjadi 0 , maka:

$$
\varepsilon=-B A \frac{d}{d t}(\cos \omega t)=B A \sin \omega t
$$

Kumparan berputar mengandung loop N, sehingga persamaannya menjadi : 


\section{$\varepsilon=N B A \omega \sin \omega t$}

\section{$=\varepsilon_{0} \sin \omega t$}

Demikian keluaran ggl adalah sinusoida dengan amplitude:

$$
\varepsilon_{0}=N B A \omega_{\cdot(5)}
$$

Konstruksi dinamo sepeda sama seperti konstruksi generator sinkron pada umumnya. Hanya saja pada bagian rotor, dinamo sepeda menggunakan magnet permanen agar tidak memerlukan lagi arus eksitasi dari luar.

\section{Stator}

Stator terdiri dari inti stator dan kumparan stator dan diletakkan pada frame depan dan belakang. Pada inti stator, dibuat dari beberapa lapis plat besi tipis. Inti stator ini akan mengalirkan flux magnet yang disuplai oleh inti rotor, sehingga flux magnet akan menghasilkan efek yang maksimum pada saat melalui kumparan stator. Hanya saja penggunaan inti besi ini akan membuat magnet pada rotor menjadi tertarik menuju inti stator yang akan membuat rotor tidak berputar bebas.

\section{Rotor}

Rotor berfungsi untuk membangkitkan medan magnet. Rotor berputar bersama poros, karena gerakannya maka disebut dengan medan magnet berputar. Medan magnet tersebut dihasilkan oleh magnet permanen yang menempel pada rotor. Oleh karena itu dinamo sepeda tidak memerlukan lagi arus eksitasi dari luar.

\section{Air Gap}

Celah udara pada generator merupakan tempat berpindahnya fluks magnet pada magnet permanen dan menginduksi ke kumparan stator. Sehingga pada celah udara ini terjadi mekanisme perpindahan atau konversi energi dari mekanik menjadi elektrik. Tentunya besar atau lebarnya celah udara ini mempengaruhi penginduksian ke kumparan stator. Pada umumnya beban yang disuplai oleh dinamo merupakan beban AC, maka dari itu tegangan keluaran dari dinamo ini tidak perlu diubah menjadi tegangan DC. Tetapi jika beban yang ingin disuplai merupakan beban DC, maka diperlukan rangkaian penyearah untuk mengkonversi tegangan AC menjadi DC.

\subsection{Rectifier}

Rectifier adalah rangkaian elektronika yang berfungsi menyearahkan tegangan AC menjadi DC. Penyearah gelombang dari bagi menjadi 2 jenis yaitu penyearah setengah gelombang dan penyearah gelombang penuh.
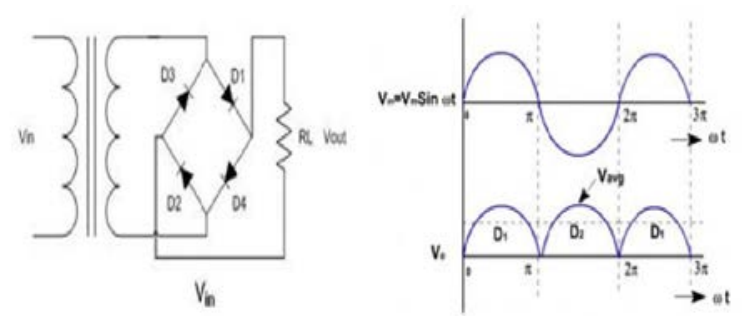

Gambar 2. Rectifier 


\subsection{Regulator}

Regulator adalah rangkaian elektronika yang berfungsi untuk membatasi tegangan arus listrik agar tidak melebihi tegangan yang diinginkan. Kinerja peralatan bisa tidak maksimal akibat tegangan arus listrik yang tidak stabil. Apabila voltage terlalu turun akan merusak peralatan dan voltage yang terlalu tinggi juga akan merusak peralatan. Pada penelitian ini membutuhkan tegangan output sebesar $5 \mathrm{~V}$. Regulator pada penelitian ini dirancang menggunakan IC regulator 7805.

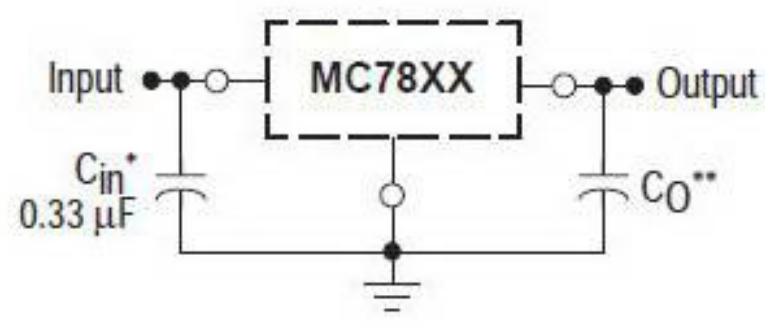

Gambar 3. Regulator

\subsection{Penguat Arus}

Jenis penguat yang digunakan adalah penguat fixed bias configuration. Kaki basis dan collector diberi tegangan dari VCC, kaki emitter transistor terhubung dengan ground. Jenis transistor yang digunakan 2N3019. Rangkaian penguat arus ini dirangkai secara umum dengan regulator positif LM7805 yang umumnya arus maksimal keluran dari LM7805 1 A, tetapi dengan memasang transistor pada rangkaian regulator maka akan menambah kekuatan arus dari regulator tersebut. Arus yang mampu mengalir adalah sesuai kemampuan transistor yang digunakan, semakin besar kemamuan dari transistor tersebut maka akan semakin besar pula arus yang akan dihasilkan.

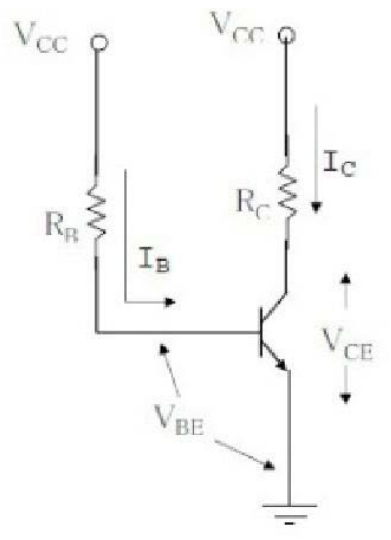

Gambar 4. Penguat Arus

\subsection{Sistem Keseluruhan}

Untuk dapat mengisi muatan pada baterai maka dibutuhkan supply arus untuk baterai. Tegangan yang diperlukan adalah $3.7 \mathrm{~V}$ untuk mengisi baterai. Tegangan yang berasal dari putaran dinamo motor dengan keluaran output tegangan sebesar $6 \mathrm{~V}-12 \mathrm{~V}$ AC. Tegangan yang dihasilkan tersebut disearahkan oleh rangkaian rectifier menjadi tegangan searah (DC) menggunakan diode bridge dan disaring menggunakan

Kapasitor (C1) $2200 \mu \mathrm{F} / 25$ volt yang bertujuan untuk memperkecil riak. Kemudian tegangan $6 \mathrm{~V}-12 \mathrm{~V}$ DC tersebut diturunkan menjadi 5V DC dengan menggunakan IC regulator 7805 . Kapasitor (C2) bertujuan untuk menjaga perubahan tegangan akibat kecepatan putaran roda motor. Menggunakan LED sebagai indikator harus dipasang resistor sebagai pengaman agar LED tidak rusak, karena resistor 
berfungsi sebagai pembatas arus. Arus yang dihasilkan dinamo kecil, sehingga dibutuhkan penguat arus. Jenis penguat arus yang dipakai jenis 2N3019.

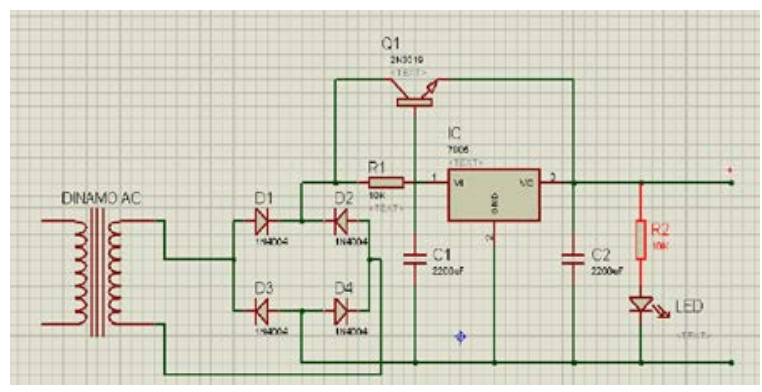

Gambar 5. Rangkaian Sistem

\section{HASIL DAN PEMBAHASAN}

\subsection{Pengujian Keluaran Dari Dinamo}

Pengujian ini bertujuan untuk membuktikan bahwa besarnya tegangan yang dihasilkan oleh dinamo tergantung pada putaran roda dan berlaku sama untuk semua roda meskipun memiliki diameter yang berbeda. Pada pengujian ini dicoba untuk membandingkan kecepatan rotor dinamo dengan diameter roda berbeda (diameter $23 \mathrm{~cm}$ dan $52 \mathrm{~cm}$ ). Kecepatan dari rotor pada dinamo diukur menggunakan tachometer. Nilai yang akan dibandingkan dari keluaran dynamo tersebut berupa nilai tegangan puncak ke puncak (Vp-p).

Tabel 1. Hubungan antara kecepatan rotor dinamo (rpm) dan V p-p (volt).

\begin{tabular}{ccc}
\hline $\begin{array}{c}\text { Kecepatan rotor dinamo } \\
\text { (rpm) }\end{array}$ & Vp-p roda diameter $\mathbf{2 3} \mathbf{~ c m}$ & Vp-p roda diameter $\mathbf{5 2} \mathbf{~ c m}$ \\
\hline 1000 & 14 & 15 \\
2000 & 22 & 23 \\
3000 & 31 & 33 \\
4000 & 41 & 44 \\
\hline
\end{tabular}

Ketika roda sepeda berputar maka rotor dinamo ikut berputar. Perputaran dari rotor dinamo menghasilkan GGL induksi. Dengan adanya GGL induksi maka dihasilkan tegangan listrik. Berdasarkan Tabel 1 percobaan dengan dua diameter roda berbeda menghasilkan nilai Vp-p yang hampir sama ketika kecepatan rotor (rpm) yang juga sama. Terlihat pada Tabel saat nilai rpm kedua roda sebesar $1000 \mathrm{rpm}$, roda dengan diameter $23 \mathrm{~cm}$ menghasilkan Vp-p sebesar 14 volt, sedangkan roda dengan diameter $52 \mathrm{~cm}$ menghasilkan Vp-p sebesar 15 volt. Sehingga tegangan yang dihasilkan bergantung pada kecepatan rotor dinamo, bukan tergantung pada besarnya diameter roda.

\subsection{Pengujian Pengisian PowerBank}

Pengujian kedua adalah pengujian pengisian PowerBank. Data pengujian baterai PowerBank dengan menggunakan spesifikasi baterai yaitu $3000 \mathrm{~mA}$. Dalam pengujian ini, prosentase baterai sebelum pengisian ditetapkan sebesar 10\%. Dari hasil pengujian menunjukkan bahwa baterai dengan spesifikasi $3000 \mathrm{~mA}$ akan mulai melakukan pengisian ketika kecepatan roda sekitar 22-25 km/jam (704-800 rpm).

Waktu pengisian baterai dalam keadaan kosong lebih singkat dibandingkan waktu pengisian baterai ketika hampir penuh. Hal ini disebabkan oleh muatan pada baterai mulai penuh sehingga muatan yang mengalir dari rangkaian akan berkurang. Baterai bermuatan sedikit lebih cepat terisi karena muatan listrik mengalir dari polaritas tinggi ke polaritas rendah. 
Hasil pengujian ini menunjukkan bahwa charger yang dibuat ternyata membutuhkan waktu yang cukup lama untuk melakukan pengisian baterai. Ketika persen awal baterai $10 \%$, untuk mencapai $11 \%$ dibutuhkan pengayuhan sekitar 10 menit dengan kecepatan stabil.

\section{SIMPULAN}

1. Semakin tinggi kecepatan putaran roda sepeda maka semakin besar tegangan listrik yang dihasilkan oleh dinamo sepeda.

2. Diameter roda sepeda yang digunakan tidak mempengaruhi besar tegangan listrik yang dihasilkan oleh dinamo sepeda.

3. Waktu pengisian baterai dalam keadaan kosong lebih singkat dibandingkan waktu pengisian baterai ketika hampir penuh.

4. Pengisian baterai dari $10 \%-11 \%$ membutuhkan waktu 10menit dengan kecepatan yang konstan.

5. Dinamo yang digunakan adalah dinamo AC sehingga dalam kasus ini harus diubah menjadi DC menggunakan rectifier.

\section{UCAPAN TERIMAKASIH}

Terimakasih banyak kepada pembimbing saya, Wisnu Broto, ST.MT yang telah membantu selama membuat serta mengerjakan makalah full paper dan kepada Prodi Elektro Fakultas Teknik Universitas Pancasila, karena telah memberikan kesempatan untuk mengikuti Seminar Nasional Fisika UNJ 2017 dan menjadi pemakalah serta membimbing untuk perisapan dalam Seminar Nasional Fisika 2017.

\section{REFERENSI}

[1] Maizir, Benni Frandinata. (2012). Charger Handphone Mekanik Dengan Memanfaatkan Energi Punggung. Penelitian Teknik Elektronika Politeknik Caltex Riau: Riau

[2] Goesbike. (2011). Nokia Bicycle Charger Kit DC 14, handphone charger. http://www.goesbike.com/articles/1474/1/Nokia-Bicycle-Charger-Kit-DC-14-handphone charger.html

[3] Zuhal.1988.Dasar Tenaga Listrik Dan Elektronika Daya.Jakarta .Gramedia.

[4] Iwan, Mahesi. (2010). Pemanfaatan putaran energi listrik Universitas Gunadarma Depok:Depok

[5] Pramudya, Y. S. 2012 pembangkit listrik tenag air menggunakan dinamo sepeda. Fakultas teknlogi industri,jurusan teknik elektro. Depok universitas Gunadarma. Jurnal 
